\title{
Molecular Patterns of Neurodevelopmental Preconditioning: A Study of the Effects of Antenatal Steroid Therapy in a Protein-Restriction Mouse Model
}

\author{
Clarissa Velayo, ${ }^{1}$ Takuya Ito, ${ }^{2}$ Yupeng Dong, ${ }^{1}$ Miyuki Endo, ${ }^{1}$ Rika Sugibayashi, ${ }^{1}$ \\ Kiyoe Funamoto, ${ }^{1}$ Keita Iida, ${ }^{1}$ Nobuo Yaegashi, ${ }^{1}$ and Yoshitaka Kimura ${ }^{1,2}$ \\ ${ }^{1}$ Department of Obstetrics \& Gynecology, Tohoku University Graduate School of Medicine, 1-1 Seiryomachi, Aoba-ku, Sendai, \\ Miyagi 980-8574, Japan \\ ${ }^{2}$ International Advanced Research and Education Organization, Tohoku University, Sendai, Miyagi 980-8574, Japan
}

Correspondence should be addressed to Clarissa Velayo; chinkeyvelayo@yahoo.com and Yoshitaka Kimura; ykimura@med.tohoku.ac.jp

Received 9 December 2013; Accepted 25 December 2013; Published 13 March 2014

Academic Editors: R. Kimmig, C. J. Petry, and K. Yang

Copyright (C) 2014 Clarissa Velayo et al. This is an open access article distributed under the Creative Commons Attribution License, which permits unrestricted use, distribution, and reproduction in any medium, provided the original work is properly cited.

\begin{abstract}
Introduction. Prenatal programming secondary to maternal protein restriction renders an inherent susceptibility to neural compromise in neonates and any addition of glucocorticosteroids results in further damage. This is an investigation of consequent global gene activity due to effects of antenatal steroid therapy on a protein restriction mouse model. Methods. C57BL/6N pregnant mice were administered control or protein restricted diets and subjected to either $100 \mu \mathrm{g} / \mathrm{Kg}$ of dexamethasone sodium phosphate with normosaline or normosaline alone during late gestation (E10-E17). Nontreatment groups were also included. Brain samples were collected on embryonic day 17 and analyzed by mRNA microarray analysis. Results. Microarray analyses presented 332 significantly regulated genes. Overall, neurodevelopmental genes were overrepresented and a subset of 8 genes allowed treatment segregation through the hierarchical clustering method. The addition of stress or steroids greatly affected gene regulation through glucocorticoid receptor and stress signaling pathways. Furthermore, differences between dexamethasone-administered treatments implied a harmful effect during conditions of high stress. Microarray analysis was validated using qPCR. Conclusion. The effects of antenatal steroid therapy vary in fetuses according to maternal-fetal factors and environmental stimuli. Defining the key regulatory networks that signal either beneficial or damaging corticosteroid action would result in valuable adjustments to current treatment protocols.
\end{abstract}

\section{Introduction}

The concept of the fetal genome is no longer that of a static framework inherited from paternal and maternal sources but a malleable scaffold constantly adapting to stimuli. This is most evident in studies involving fetal programming due to the effects of nutritional variation and glucocorticoid exposure [1]. Here, we examined the resulting fetal molecular preconditioning due to antenatal steroid therapy using a protein-restriction mouse model. This model was first designed in a previous study [2] as a novel approach to evaluate postnatal adaptive responses due to varied prenatal nutritional conditions and the addition of stress or steroids.
Molecular evidence revealed that prenatal programming secondary to maternal protein restriction rendered an inherent susceptibility to neural compromise in neonates and any further addition of antenatal steroids may be detrimental to these already injury-prone offspring. Thus, an examination of underlying molecular mechanisms in the fetus was warranted to elucidate the effects seen postnatally.

Understanding any subtle changes in the fetus induced by these factors and their correlation with phenotypic outcomes in the adult would facilitate early detection of either wellbeing or disease. Current biomolecular techniques such as microarray analysis have allowed the investigation of global gene expression and subsequently, the parallel data mining 
of gene transcripts of interest as well as the discovery of new gene involvement. Moreover, gene expression profiles through clustering of significant genes have shown promising potential as diagnostic panels. All these have led to the rapid identification of biomarkers for disease conditions and their associated regulatory pathways [3]. Using these advancements, a panoramic view of genetic movement in utero is presented.

\section{Materials and Methods}

2.1. Experimental Animals. Female C57BL/6N mice about 6 weeks old provided by the Institute for Animal Experimentation, Tohoku University Graduate School of Medicine, were maintained under controlled lighting (12-hour light cycles) and temperature $\left(24^{\circ} \mathrm{C}\right)$. These were allowed for free access to food (AIN-93G: Oriental Yeast Co., Ltd., Tokyo, Japan) and water during a 2-week acclimatization period after which each female was time mated with a male.

2.2. Treatment Groups. Pregnant females $(n=36)$ were then housed singly and administered either control (C) or protein restricted (PR) diets ad libitum all throughout pregnancy (Embryonic stage, E0 to E17). These were then further subdivided into 6 groups and subjected to either plain normosaline solution (C-S, PR-S) or $100 \mu \mathrm{g} / \mathrm{Kg}$ dexamethasone sodium phosphate (Decadron, MSD K.K., Tokyo, Japan) in normosaline solution (C-D/S, PR-D/S) by subcutaneous injection daily during late gestation (E10 to E17). Nontreatment groups were also included (C, PR). All injections were performed between $12 \mathrm{nn}$ and $2 \mathrm{pm}$. Maternal weights on days E0, E10, and E17 were recorded, as well as fetal weights on E17. On embryonic day 17, whole brain samples collected from 2 male and 2 female fetuses from each litter were supercooled in liquid nitrogen and stored at $-80^{\circ} \mathrm{C}$.

2.3. DNA Chip Analysis. A total of 6 Toray 3D-Gene Mouse Oligo chip $24 \mathrm{~K}$ (Toray Industries, Inc., Tokyo, Japan) microarrays were analyzed per treatment. Each chip utilized a $0.5 \mu \mathrm{g}$ portion of combined total RNA from a matched pair of male and female samples. RNA was amplified and labeled using an Amino Allyl MessageAmp II aRNA Amplification kit (Life Technologies Japan Ltd.) according to the manufacturer's instructions. Each sample of aRNA was labeled with fluorescence Cy3 or Cy5 and cohybridized at $37^{\circ} \mathrm{C}$ for 16 hours. These were subsequently washed and dried. Hybridization signals were scanned using Scan Array Express (Perkin Elmer, MA, USA) and global background analysis was performed using GenePx Pro (MDS Analytical Technologies, CA, USA). All 36 arrays were then normalized together as one experiment to reduce nonbiological variability.

2.4. Quantitative PCR ( $q P C R$ ). To validate microarray results, qPCR was performed on 2 selected genes, microtubule-associated protein $1 \mathrm{~b}$ (Mtaplb) and 3-hydroxy-3methylglutaryl-CoA synthase 1 (Hmgcs1), using the $\mathrm{C}$ and C-D/S treatments. Total RNA was extracted from whole fetal brains ( $n=6$ per treatment) using QIAzol Lysis Reagent (QIAGEN, Hilden, Germany) and cleaned with an AllPrep DNA/RNA Mini kit (QIAGEN, Hilden, Germany) according to the manufacturer's protocol. Complimentary DNA was synthesized using the Superscript III First-Strand Synthesis System (Invitrogen, Carlsbad, CA) and quantitative PCR was conducted with EXPRESS SYBR GreenER Supermix with Premixed ROX (Invitrogen, Carlsbad, CA) on an Eppendorf Realplex ${ }^{2}$ Mastercycler (Eppendorf, Hamburg, Germany). Amplified transcripts were quantified and normalized against hypoxanthine phosphoribosyltransferase 1 (Hprt1). Primer sequences of the selected genes and housekeeping gene are provided.

2.5. Statistical Analysis. Microarray data were subjected to $t$-test analyses with standard Bonferroni correction for multiple comparisons. The $P$ value was set at 0.05 and a threshold of 1.5-fold was applied to determine significantly regulated genes. These were subjected to an ontological review and a subset of neurodevelopmental genes for genetic profiling was determined by hierarchical clustering. Targeted gene transcripts of interest on the microarrays were treated to one-way ANOVA with post-hoc analysis (Bonferroni post-test). Confirmation of selected genes by qPCR was validated through Fold Change Analysis (threshold of 1.5-fold). Data management, statistical analysis, and gene ontology were performed using geWorkbench software (https://gforge.nci.nih.gov/frs/?group_id=78) and MGI Gene Ontology Tools (http://www.informatics.jax.org/gotools/).

\section{Results}

3.1. Mouse Model. Mean maternal weight gain patterns, between groups, were similar before (E0 to E10) and during treatment (E10 to E17). Mean fetal brain to body weight indices on sampling day E17 were not significantly different (Figure 1).

3.2. Global Gene Changes. Microarray analyses of 23,522 probe transcripts presented 10,946 genes without absent calls or unreadable hybridization signals. There were more upregulated genes as compared to downregulated genes across all treatment groups (Figure 2, Table 1). The combined number of significant genes regulated from all treatment groups versus the control was 332 (Figure 3). Subsequent gene ontology analysis revealed that ongoing cell organization and biogenesis, developmental processes, and transport were most rampant in the global expression survey. The discovery of genes uniquely activated per treatment and sharing similar ontologies facilitated individual treatment characterization (Table 2(a)). Associated genes were found for protein restriction, cell adhesion genes in both PR-D/S only (Colla1, Atp1b2, Ctnnd1, Rpsa, and Fat4), and PR-S only (Cdh2, Edil3, and Astn1); for dexamethasone treatment, stress response genes in both C-D/S only (Brsk1, Rarres2), and PRD/S only (Klk8, Myo6, Ndufa6, Colla1, Mapk8, and Phlda3); and for both protein restriction, dexamethasone treatment, and DNA metabolism genes for PR-D/S only (Tcf3, Mapk8). 


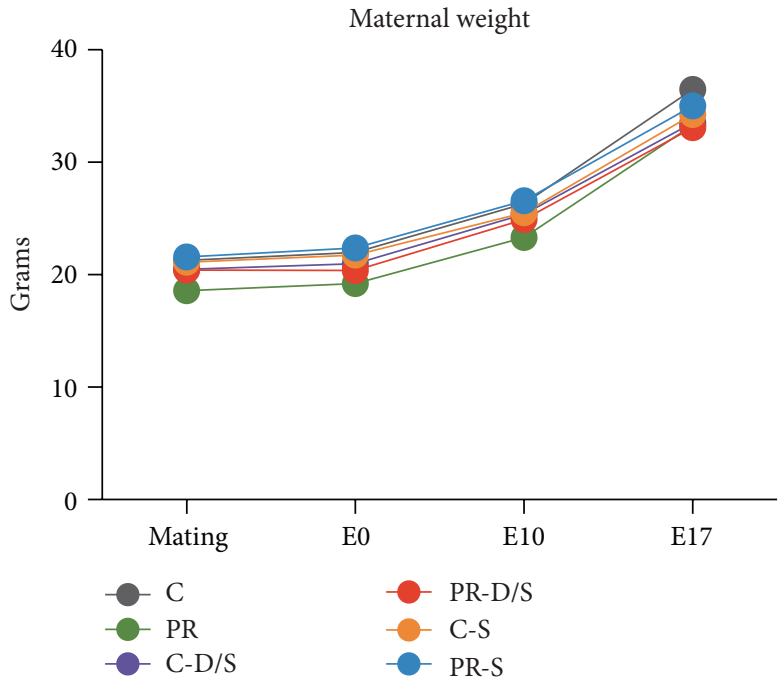

(a)

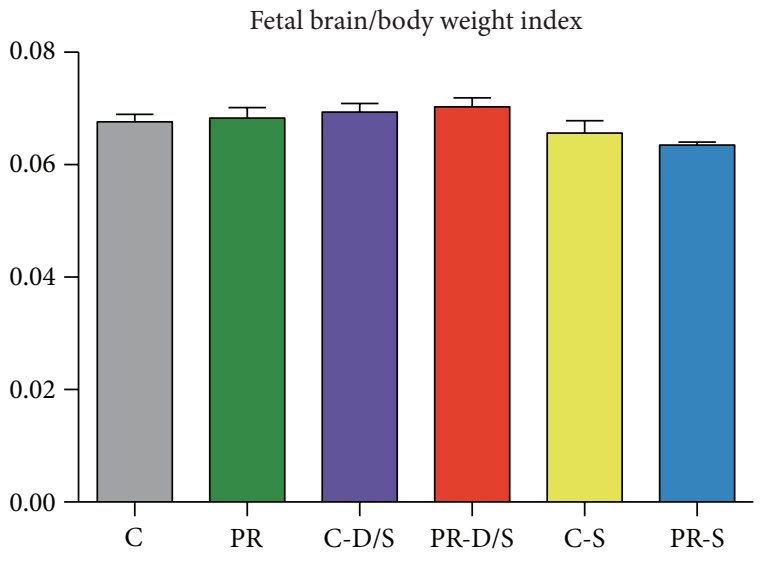

(b)

Figure 1: Effects of treatment on animal models. (a) Each data point represents maternal weight as mean \pm SEM ( $n=4$ per treatment). Two-way ANOVA indicates a significant treatment effect $(P<0.0001)$ and time effect $(P<0.0001)$. Bonferroni posttest indicates that all treatments were similar to the $\mathrm{C}$ group. (b) Mean fetal brain to body weight indices across treatments \pm SEM were not significantly different by one-way ANOVA $(n=96)$.

Overall, neurodevelopmental genes were overrepresented among those significantly regulated (Table 2(b)) and were associated with nervous system development (Pbx3, Eif2b5, Nlgn1, Mark4, Atp2b2, Nrxn3, Ncam1, Tnik, Slitrk1, Cdh2, Synj1, Palm, Nrp1, Rpl24, Mtap2, Rpgrip1, Pou3f2, Gabrb3, Lrp6, Sulf2, Ank3, Ccdc88a, Atrx, Nr2c2, Opa1, Abi2, Mtap1b, Tcf3, Syne1, Mapk8, Golga2, Atxn2, Gfra1, Snap91, Slitrk5, Celsr2, Emx2, Klk8, Myo6, Scn2a1, Sema3c, and Kif5c); generation of neurons (Pbx3, Nlgn1, Atp2b2, Ncam1, Tnik, Slitrk1, Cdh2, Synj1, Palm, Nrp1, Rpl24, Mtap2, Rpgrip1, Pou3f2, Gabrb3, Lrp6, Ank3, Ccdc88a, Abi2, Mtap1b, Tcf3, Syne1, Mapk8, Golga2, Atxn2, Gfra1, Slitrk5, Snap91, Celsr2, Emx2, Klk8, Myo6, Sema3c, Kif5c, Robo2, Arhgef2, Brsk1, Pou3f4, and Sox11); neuron differentiation (Pbx3, Nlgn1, Atp2b2, Ncam1, Tnik, Slitrk1, Cdh2, Palm, Nrp1, Rpl24, Mtap2, Rpgrip1, Pou3f2, Gabrb3, Lrp6, Ank3, Ccdc88a, Abi2, Mtap1b, Tcf3, Syne1, Mapk8, Golga2, Gfra1, Atxn2, Slitrk5, Snap91, Celsr2, Emx2, Klk8, Myo6, Sema3c, Kif5c, Robo2, Brsk1, Pou3f4, and Sox11); neurogenesis (Pbx3, Eif2b5, Nlgn1, Atp2b2, Ncam1, Tnik, Slitrk1, Cdh2, Synj1, Palm, Nrp1, Rpl24, Mtap2, Rpgrip1, Pou3f2, Gabrb3, Lrp6, Ank3, Ccdc88a, Abi2, Mtaplb, Tcf3, Syne1, Mapk8, Golga2, Atxn2, Gfra1, Slitrk5, Snap91, Celsr2, Emx2, Klk8, Myo6, Sema3c, Kif5c, Robo2, Arhgef2, Brsk1, Pou3f4, and Sox11); neuron development (Pbx3, Abi2, Mtap1b, Syne1, Mapk8, Golga2, Nlgn1, Atxn2, Gfra1, Snap91, Slitrk5, Celsr2, Atp2b2, Ncam1, Tnik, Slitrk1, Klk8, Cdh2, Myo6, Sema3c, Palm, Kif5c, Nrp1, Rpl24, Robo2, Mtap2, Rpgrip1, Brsk1, Pou3f2, Gabrb3, Ank3, and Ccdc88a); and neuron projection development (Abi2, Mtap1b, Syne1, Mapk8, Golga2, Nlgn1, Atxn2, Gfra1, Snap91, Slitrk5, Celsr2, Ncam1, Tnik, Slitrk1, Klk8, Cdh2, Myo6, Sema3c, Palm, Kif5c, Nrp1, Rpl24, Robo2, Mtap2, Brsk1, Pou3f2, Ank3, and Ccdc88a).
TABLE 1: Summary of significantly regulated genes. Determination of upregulated and downregulated significant genes based on paired $t$-tests with standard Bonferroni correction for multiple comparisons $(P<0.05$; thresholds of $>1.5$ for upregulated genes and $<-1.5$ for downregulated genes).

\begin{tabular}{lccc}
\hline \multirow{2}{*}{$t$-test ${ }^{*}$} & \multirow{2}{*}{ Regulated genes } & \multicolumn{2}{c}{ Fold change } \\
& & $\uparrow(>1.5)$ & $\downarrow(<-1.5)$ \\
\hline C versus PR & 4 & 0 & 0 \\
C versus C-D/S & 751 & 91 & 24 \\
C versus PR-D/S & 974 & 158 & 44 \\
C versus C-S & 896 & 141 & 25 \\
C versus PR-S & 1125 & 184 & 40 \\
\hline
\end{tabular}

${ }^{*} P<0.05$.

3.3. Gene Expression Profiling. A subset of 8 genes out of 332 was filtered through the hierarchical clustering method allowing segregation of treatments (Figure 4). An assessment of individual biological themes within the subset revealed neurodevelopmental roles and distinct causal relationships with glucocorticoid treatment and protein restriction (Table 3).

3.4. Targeted Genes of Interest. The addition of stress or steroids ( $-S$ and $-D / S$ groups) greatly affected gene regulation leading to further investigation of genes related to glucocorticoid and stress signaling pathways. Mapk8, Fkbp5, Mkp-1, Pp2A, Akt, and Gsk3 exhibited expression patterns across treatment groups that corresponded to an overall reduction in glucocorticoid receptor (GR) activity in the $-D / S$ and $-S$ groups. Most significant of which were the marked differences between $\mathrm{C}-\mathrm{D} / \mathrm{S}$ and $\mathrm{PR}-\mathrm{D} / \mathrm{S}$ 

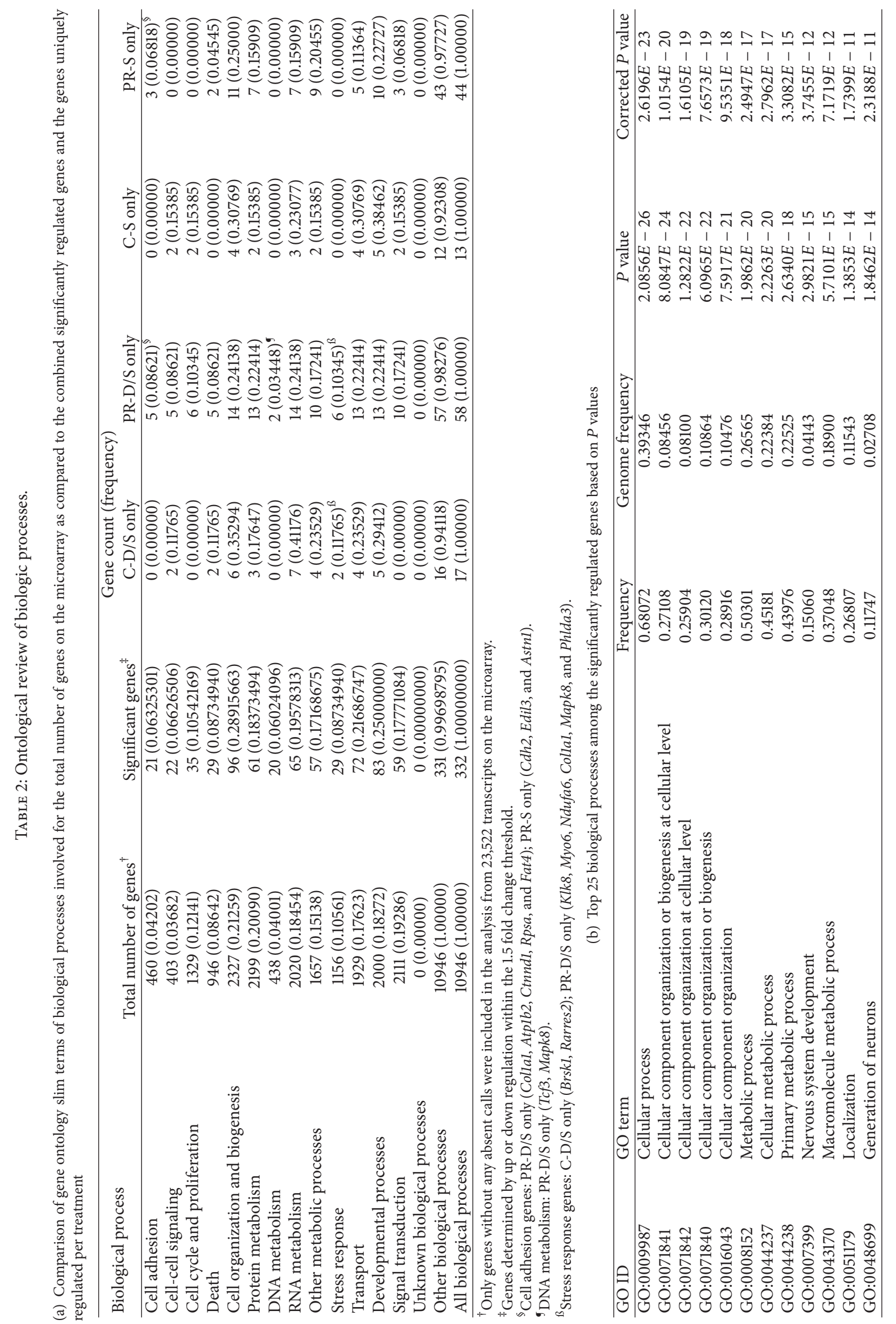


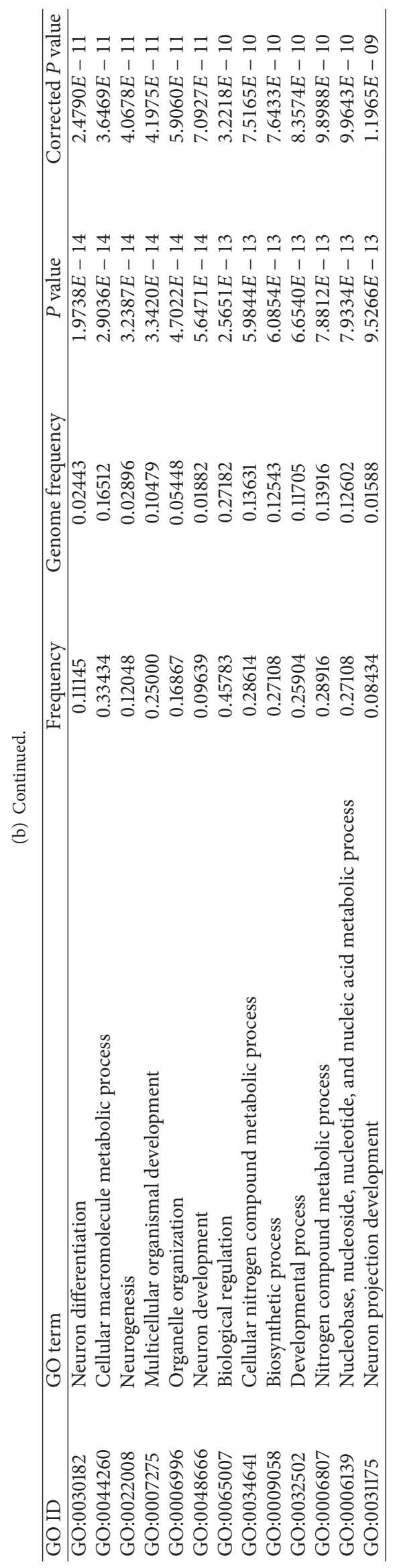




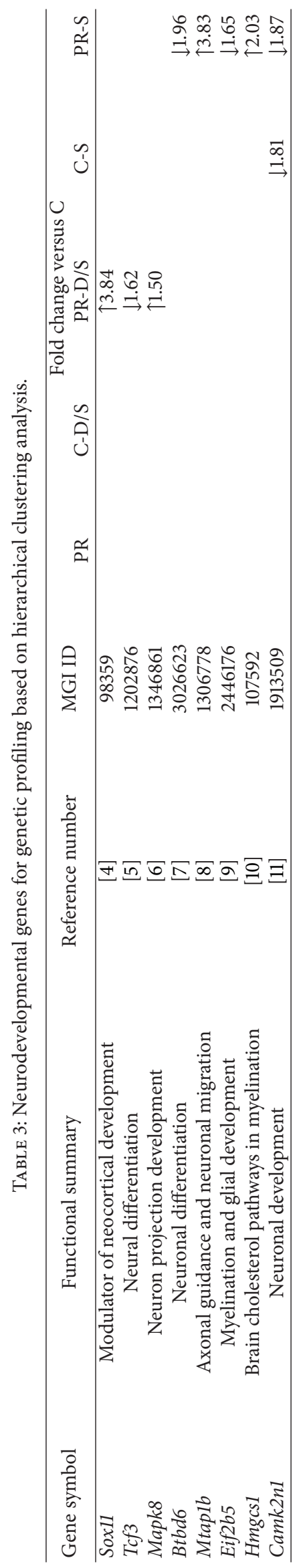




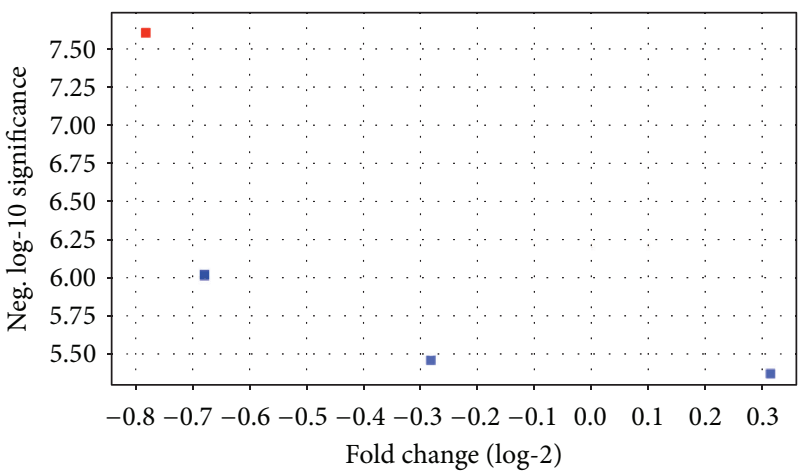

(a) $\mathrm{C}$ versus $\mathrm{PR}$

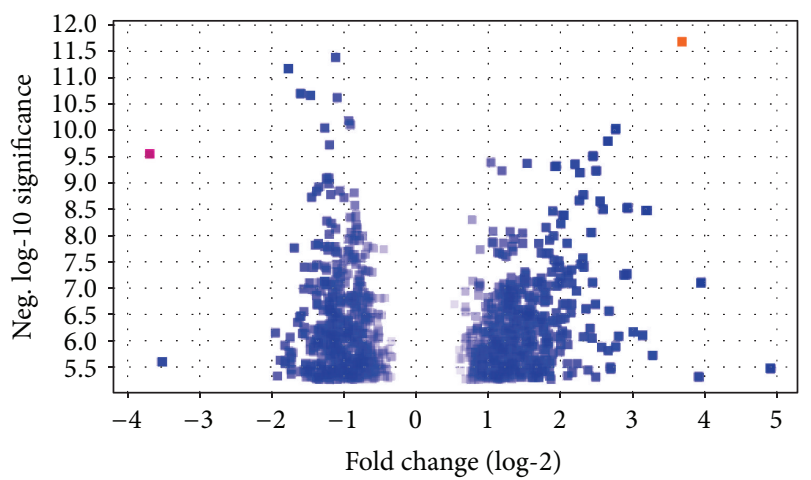

(c) $\mathrm{C}$ versus $\mathrm{PR}-\mathrm{D} / \mathrm{S}$

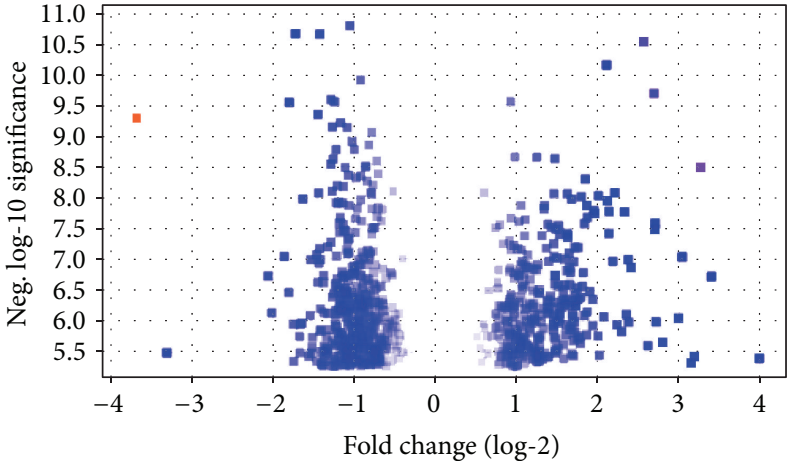

(b) $\mathrm{C}$ versus $\mathrm{C}-\mathrm{D} / \mathrm{S}$

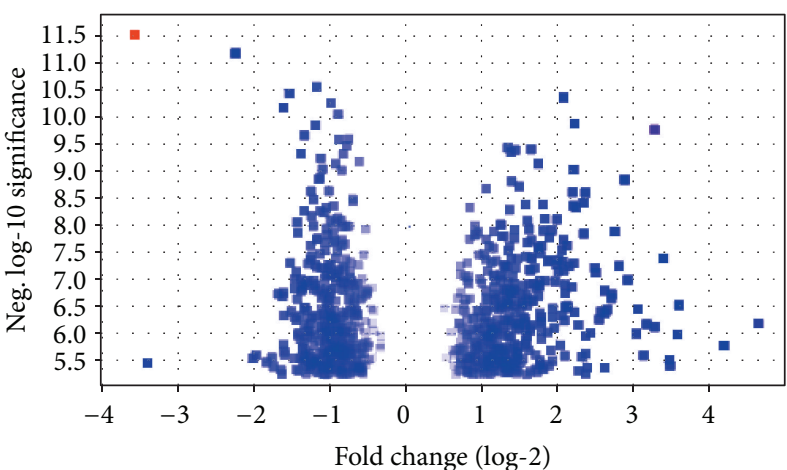

(d) C versus C-S

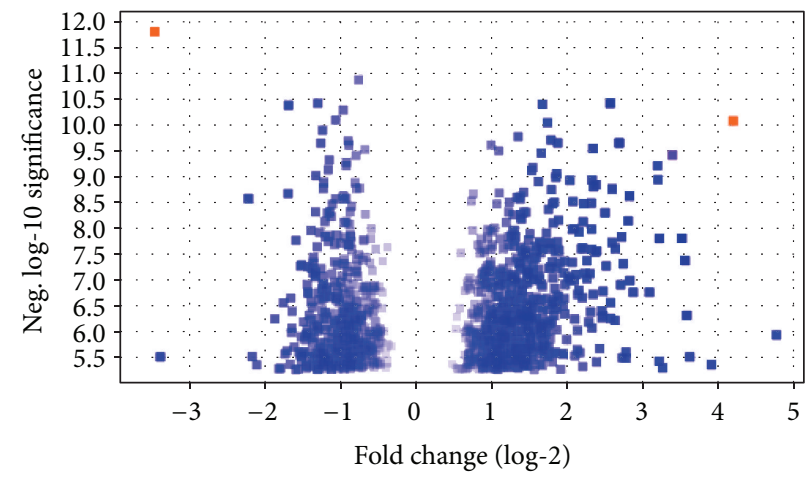

(e) C versus PR-S

Figure 2: Volcano plots of individual $t$-test analyses using Standard Bonferroni correction and $P<0.05$ between the control group and all other treatment groups.

(Mapk8, Gsk3, and Mtap1b) emphasizing the disparate effect on varying nutritional conditions due to dexamethasone administration (Figures 5(a) and 5(b)).

3.5. Quantitative PCR Validation. $\mathrm{qPCR}$ results demonstrated a good agreement with the microarray data for Mtaplb and Hmgcs1 (Figure 6).

\section{Discussion}

The maternal-fetal compartment serves to cushion the fetus from environmental stimuli, but beyond normal circumstances, prenatal conditioning invariably occurs. Microarray analysis allowed for a panoramic view of gene activity along two levels: through the global expression of genes and through individual treatment groups and their association with one another. In general, ongoing cell organization and biogenesis, developmental processes, and transport were most rampant in the global expression survey (Table 2(a)). The dominance of these particular gene groups is expected in the developing fetus just as genes for growth and maturation are more likely activated in neonates. Regardless, these increased gene frequencies most likely demonstrate consequent fetal reactions to acquired insults from protein restriction and glucocorticoid exposure either as compensatory regulation or protective feedback. They signaled changes 


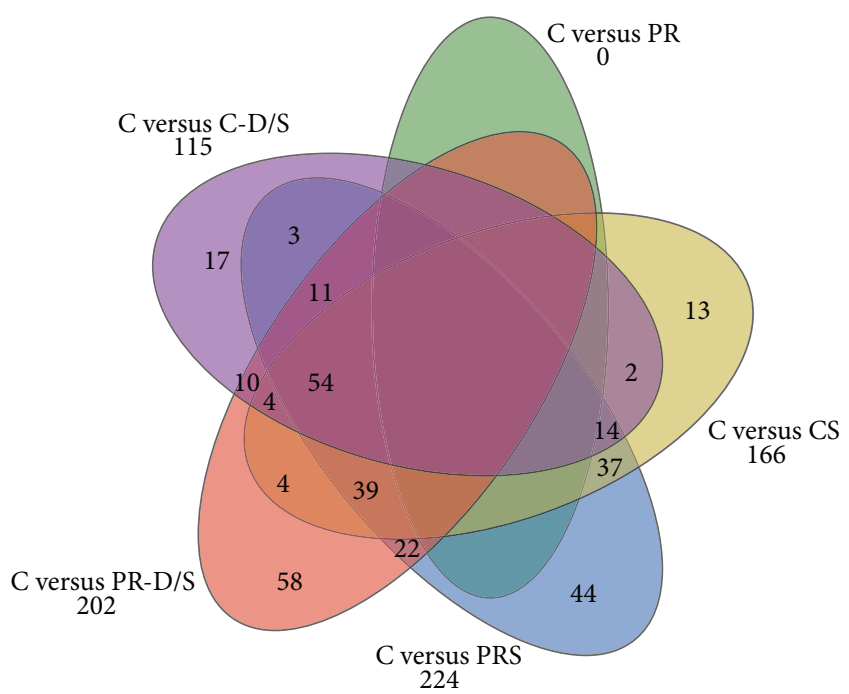

FIgURE 3: Diagram of 332 significant genes showing areas of overlapping regulation between treatments.

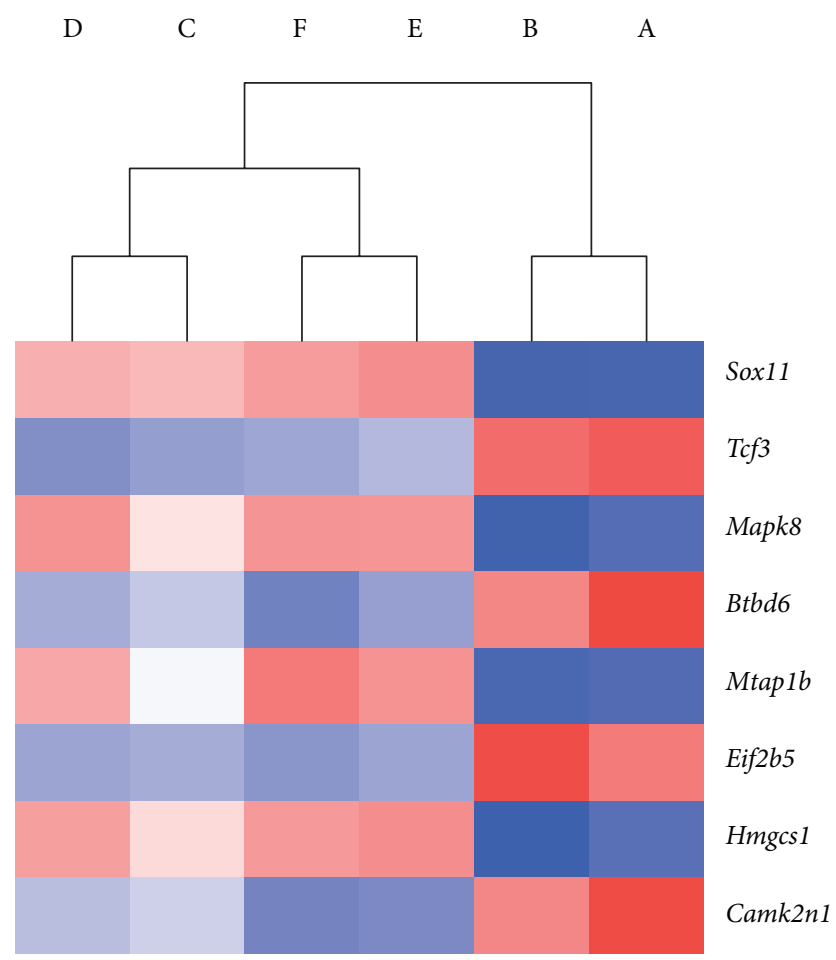

FIGURE 4: Hierarchical clustering using the average linkage method and Pearson's correlation as the clustering metric resulted in 8 neurodevelopmental genes for genetic profiling: (A) C; (B) PR; (C) C-D/S; (D) PR-D/S; (E) C-S; (F) PR-S.

within a fetus long previously believed to be immune prior to the conception of the Barker theory [12].

Interestingly, neurodevelopmental genes were overrepresented among the significantly regulated genes. This was exemplified by recurring themes in biological processes related to ongoing brain development during fetal stages: multipotent progenitor differentiation and neuronal migration. Their increased expression over other gene systems emphasized the significance of fetal neuroplasticity even to the detriment of visceral organ growth similar to physiologic brain sparing. This also underlined the early dependence on brain-controlled pathways that trigger bodily functions during stages when less developed organs have not yet attained full functional independence.

Our mouse model simulated conditions of multifactorial environmental impact. The isolation of distinct genes associated with individual factors of protein restriction, dexamethasone, and stress were complimentary to known gene networks.

4.1. Protein Restriction Associated with Cell Adhesion Genes. Maternal nutrition plays a critical role in fetal growth and development. Studies of these genes uniquely regulated in both PR-D/S (Colla1, Atp1b2, Ctnnd1, Rpsa, and Fat4) and PR-S only (Cdh2, Edil3, and Astn1) emphasized the crucial role of nutritional factors in maintaining the integrity of cell interaction. Collal, a known marker of fibrosis and aging, has been linked to alterations in oxidative and antioxidant defense capacity in cells due to poor maternal nutrition [13]. On the other hand, modifications in Atp1b2, Edil3, and Astn1 during development lead to glial dysfunction [14-16]. Moreover, various studies on nutritional factor effects and progenitor cell differentiation included Ctnnd1, Fat4, and Cdh2 [17-19].

4.2. Dexamethasone Associated with Stress Response Genes. Fetal dexamethasone exposure impairs development in various cell types eliciting a dose-dependent stress response [20]. In the brain, the pituitary is the site of action of administered dexamethasone in the blockade of stress induced hypothalamic-pituitary axis (HPA) activation. The latter involves the stimulation of brain receptors, primarily, those of glucocorticoid receptors (GR) by both exogenous and endogenous corticosterone. During conditions of stress, the HPA axis releases reactive feedback which suppresses increased excitability allowing recovery from stress induced activation and facilitation of memory storage. The addition of dexamethasone can partially deplete the brain of corticosterone and in turn suppress the fetal HPA axis. Studies that included the genes uniquely regulated in C-D/S (Brskl, Rarres2) and PR-D/S (Klk8, Myo6, Ndufa6, Colla1, Mapk8, and Phlda3) report their important roles in neuroregulation and adaptation to stress responses during brain development [21-25]. Furthermore, expression patterns of targeted genes related to stress signaling pathways revealed decreased GR activity: Mapk8 (mitogen activated protein kinase 8) and Fkbp5 (FK506 binding protein 5), both GR inhibitors [26, 27], were increased in the -D/S and -S groups; $M k p 1$ (mitogen activated protein kinase phosphatase 1) and $P p 2 a$ (protein phosphatase 2), both Map kinase inhibitors [28, 29], were decreased in the $-D / S$ and $-S$ groups (Figure 5(a)).

4.3. Convergent Effects of Maternal Nutrition and Dexamethasone Associated with DNA Metabolism. Genes associated with PR-D/S only (Tcf3 and Mapk8) on microarray analysis, 

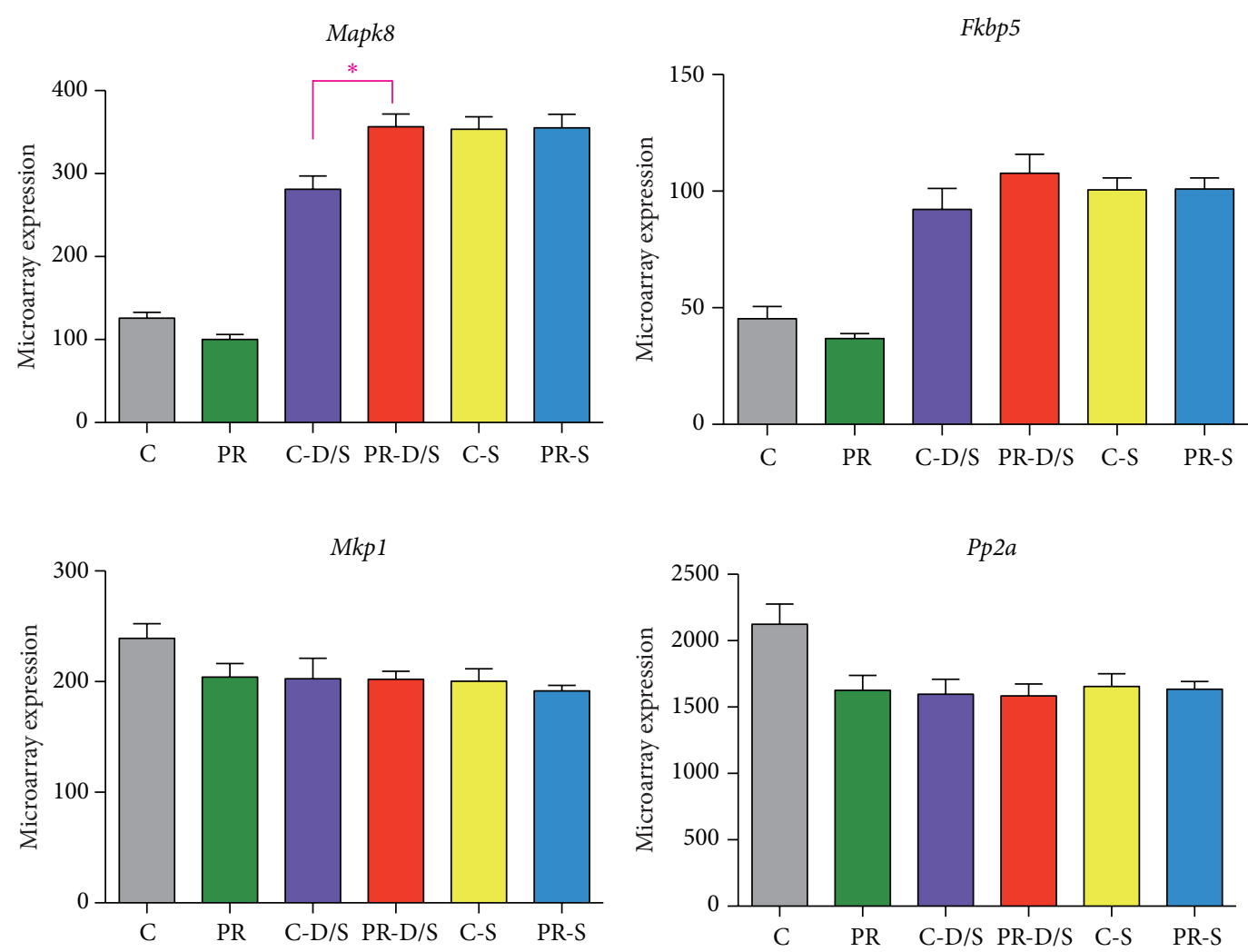

(a)
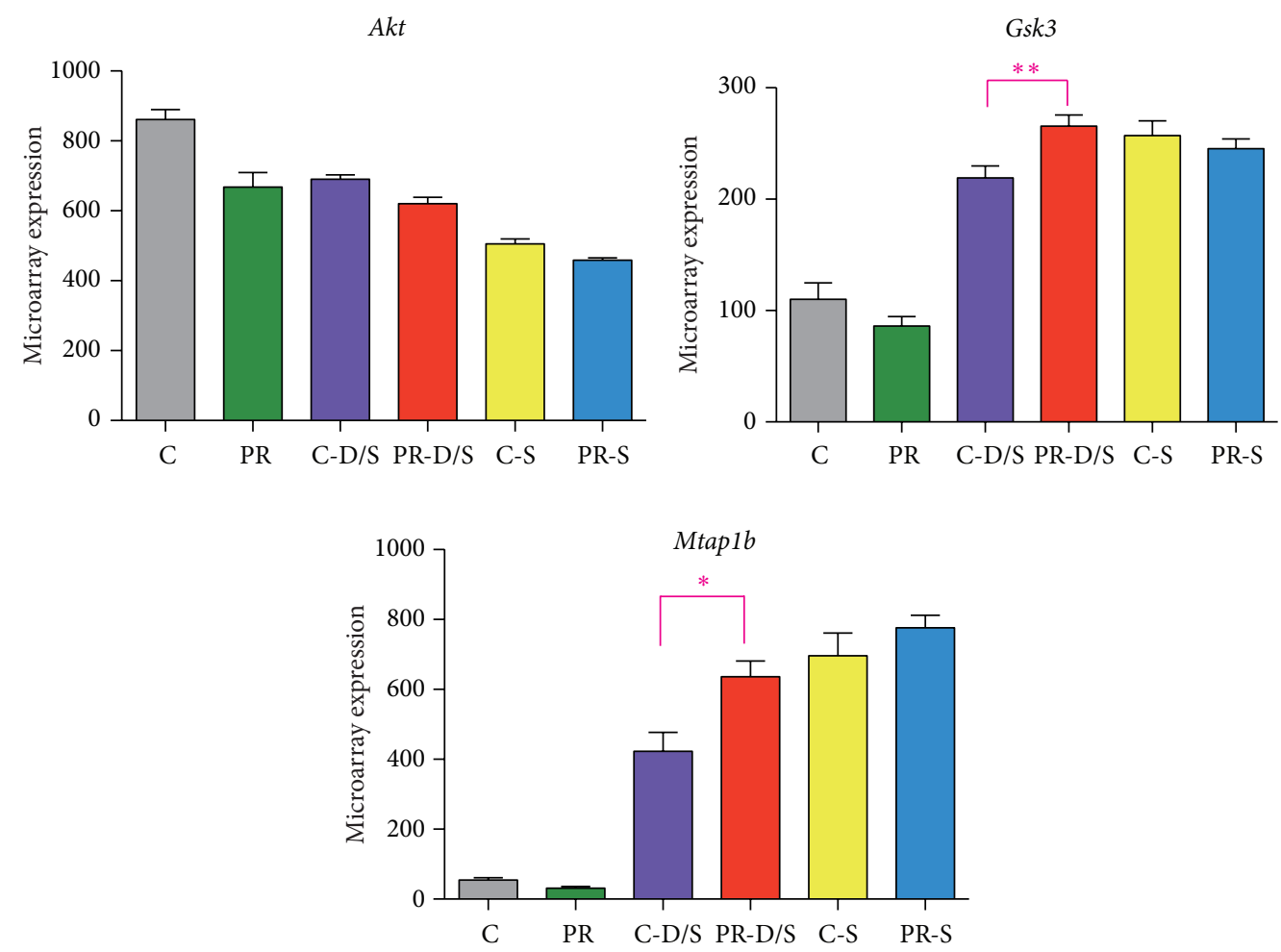

(b)

FIGURE 5: Targeted genes of interest related to stress signaling pathways. (a) One-way ANOVA of gene expression patterns revealing an overall reduction of glucocorticoid receptor (GR) activity included Mapk8, Fkbp5, Mkp1, and Pp2A. (b) One-way ANOVA of gene expression patterns for $A k t$ and Gsk3 and Mtap1b revealing ongoing neurodysgenesis $(n=6$ per treatment; mean \pm SEM; one-way ANOVA $P<0.0001$; Bonferroni ${ }^{*} P<0.05$ and $\left.{ }^{* *} P<0.1\right)$. 
Microarray

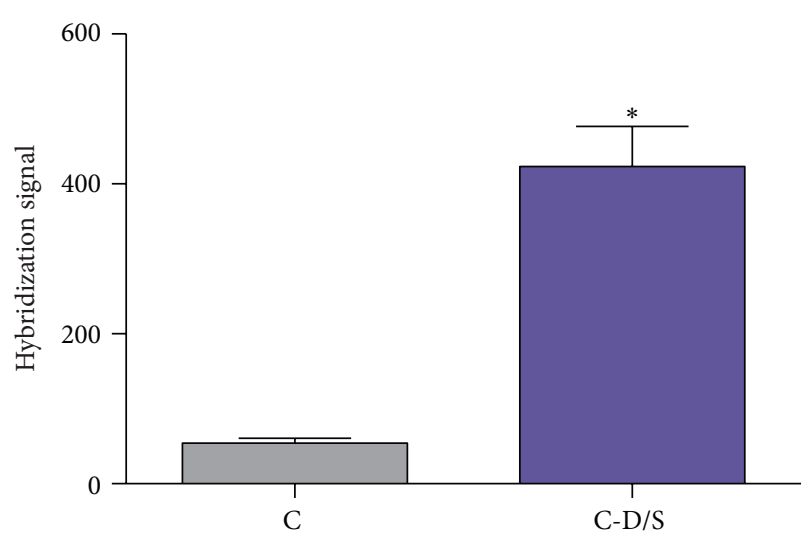

(a)

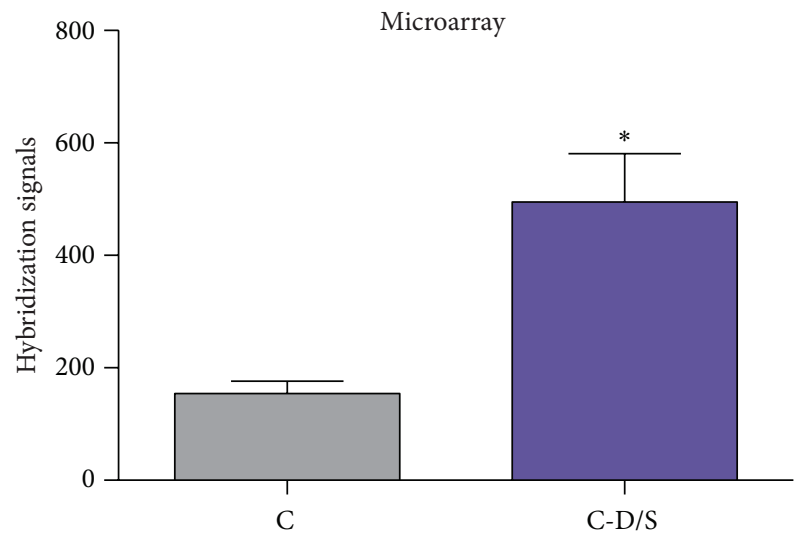

qPCR
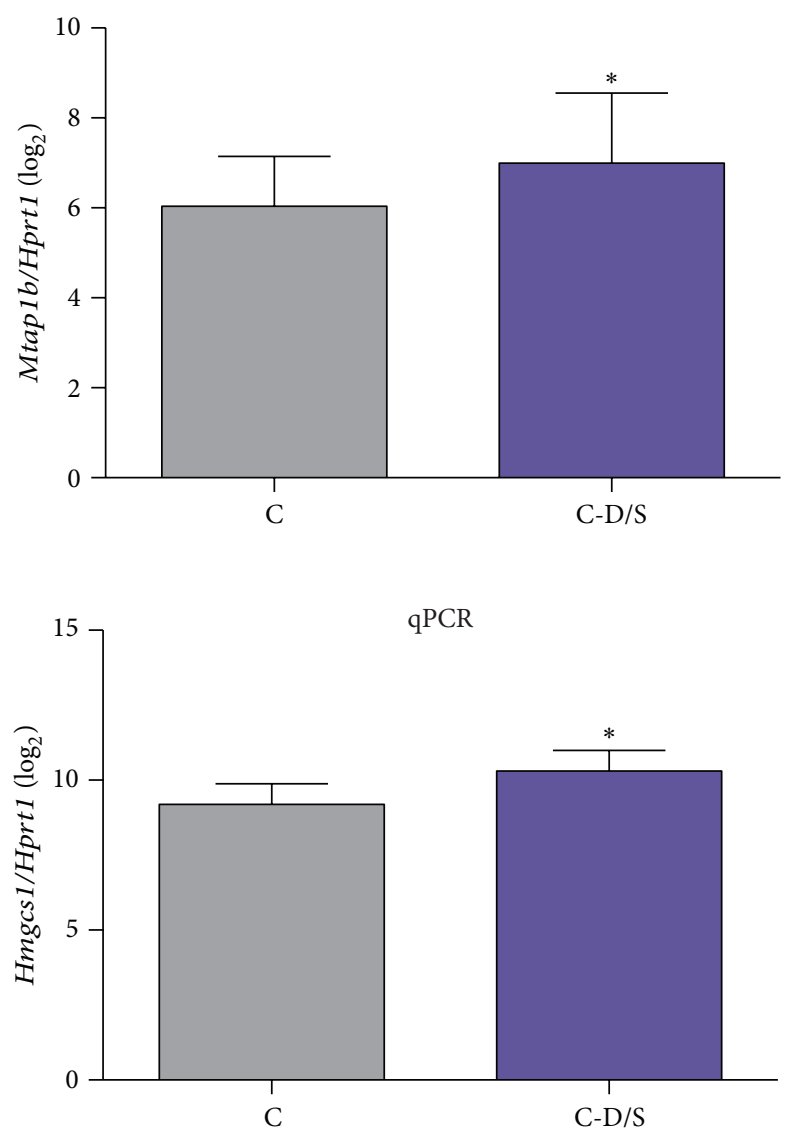

(b)

FIGURE 6: qPCR validation of microarray analysis. Two neurodevelopmental genes, Mtap1b and Hmgcs1, that were significantly changed between $\mathrm{C}$ and C-D/S groups in the microarray analysis (represented as mean hybridization signals + SEM) were compared with qPCR (mean \pm SEM transcript signals normalized against Hprt1). When comparing non-logged fold changes by the ratio method, there was an overall good agreement between qPCR and microarray analysis with a fold change of at least $1.5^{*}$ observed. $(n=6$ per treatment).

as well as two targeted genes (Akt and Gsk3) all function in metabolic gene networks, especially for glucose metabolism in DNA synthesis. Here, their specific expression patterns between -D/S groups underscored the most significant observation in this study, which was the apparent harmful effect of dexamethasone to fetuses in highly stressed conditions (PR$\mathrm{D} / \mathrm{S})$. A diagram interrelating the targeted genes of interest with regard to GR activity is shown in Figures $7(\mathrm{a})$ and 7(b). Previous reports have stated that a loss of GR activity reduces dexamethasone inhibition of Akt (thymoma viral protooncogene 1), which in turn decreases $A k t$ inhibition of Gsk3 (glycogen synthase kinase 3), a proapoptotic gene [3032]. This beneficial effect was seen in the C-D/S group. But in the PR-D/S group, a highly stressed condition, dexamethasone was evidently harmful. This disparate pattern between C-D/S and PR-D/S, significant in Mapk8, Gsk3, and Mtap1b $(P<0.0001)$, denotes the possibility of ongoing altered neurodevelopment or even neurodysgenesis (Figure 5(b)).

The process of data mining revealed the association between regulated genes unique to individual treatment groups and certain biologic processes. Their correlation provided a better understanding of underlying pathophysiology and a glimpse of key pathways for future focused studies. One possible application is the development of gene panels for genetic expression profiling as diagnostic tools. Hierarchical clustering programs currently allow the generation of gene maps to be capable of distinguishing between phenotypes. In our simulation, highly regulated neurodevelopmental genes were used and these successfully segregated treatments between microarrays (Figure 4).

Our findings strengthen our previous study's assertion that fetal programming secondary to maternal protein restriction renders an inherent susceptibility to neural compromise in offspring and that the addition of dexamethasone to this vulnerable group results in further injury. In future studies, the investigation of both sex-specific and transgenerational effects is necessary as glucocorticoids influence endocrinological pathways differently in males and females. Also, timing of exposure to glucocorticoids as well as dosage studies is no less relevant especially in the light of reported 


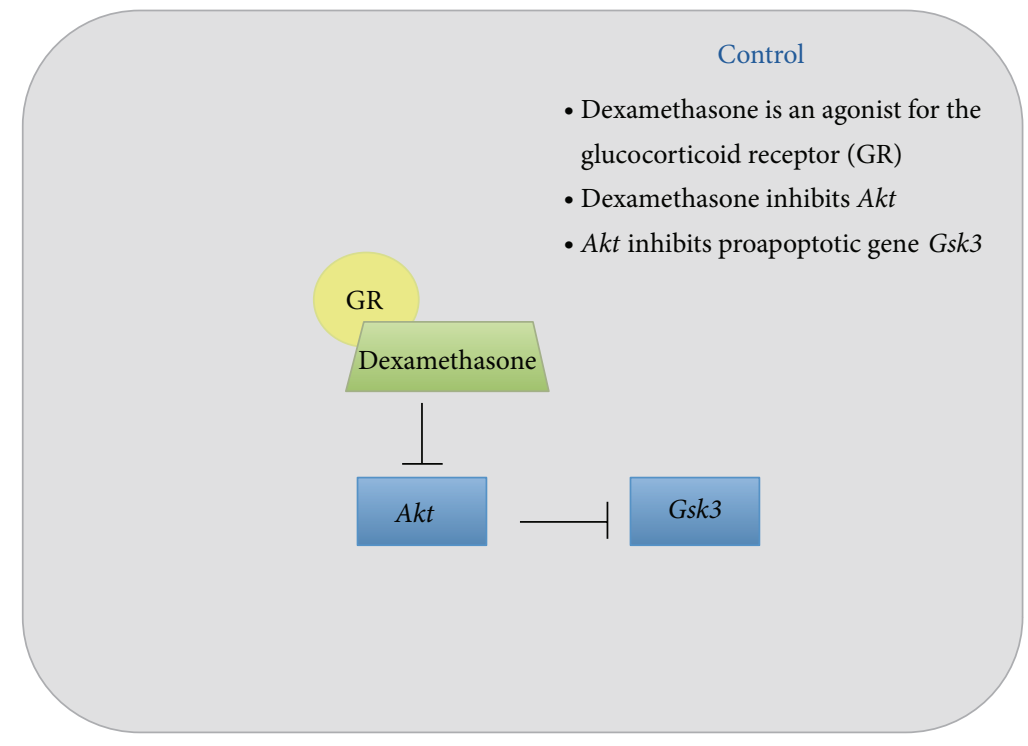

(a)

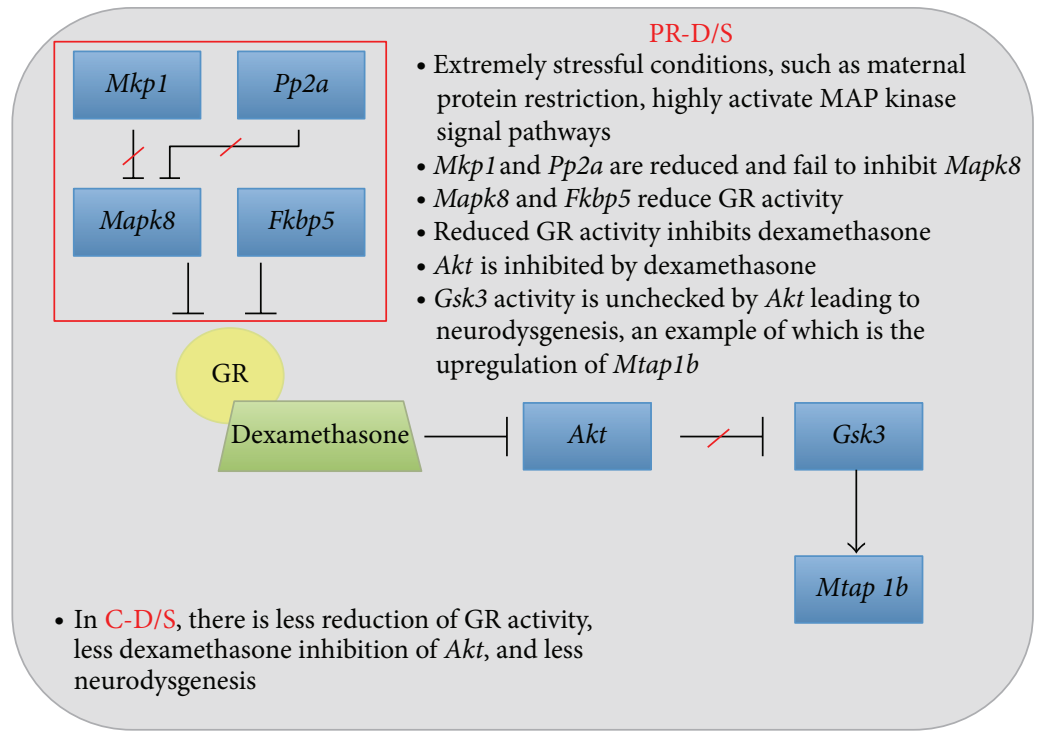

(b)

FIgURE 7: A diagram interrelating the targeted genes of interest with regards to conditions in the control and -D/S groups. (a) Control group and (b) -D/S groups.

evidence that a single course of therapy profoundly affects the fetal HPA axis [33-35].

In conclusion, the effects of antenatal steroid therapy can vary for each fetus according to maternal-fetal factors and concurrent environmental stimuli. Further elucidating regulatory networks that can mark the turning point between beneficial or damaging corticosteroid actions would result in valuable adjustments of current treatment protocols. The ability to recognize conditions highly vulnerable to damage would also expand the possibility of tailored medicine more suitable to each individual's needs. Current biomolecular techniques are powerful tools in this field of study but further validation between animal and true clinical models is required.

\section{Conflict of Interests}

The authors hereby disclose that there was no financial or personal conflict of interests involved.

\section{Acknowledgments}

The authors would like to thank Ms. Yukari Onuma and Ms. Asami Katsumata for their valuable assistance. All experimental procedures were done according to the rules of ethics and conduct of the Institute for Animal Experimentation, Tohoku University Graduate School of Medicine, Sendai, Japan. 


\section{References}

[1] H. A. de Boo and J. E. Harding, "The developmental origins of adult disease (Barker) hypothesis," Australian and New Zealand Journal of Obstetrics and Gynaecology, vol. 46, no. 1, pp. 4-14, 2006.

[2] C. Velayo, T. Ito, H. Chisaka, N. Yaegashi, K. Okamura, and Y. Kimura, "Effects of antenatal steroid therapy on neurodevelopment in an IUGR mouse model," Fetal Diagnosis and Therapy, vol. 28, no. 2, pp. 79-86, 2010.

[3] S. M. Yoo, J. H. Choi, S. Y. Lee, and N. C. Yoo, "Applications of DNA microarray in disease diagnostics," Journal of Microbiology and Biotechnology, vol. 19, no. 7, pp. 635-646, 2009.

[4] Y. Li, J. Wang, and Y. Zheng, "Soxll modulates neocortical development by regulating the proliferation and neuronal differentiation of cortical intermediate precursors," Acta Biochimica et Biophysica Sinica, vol. 44, pp. 660-668, 2012.

[5] T. Ohtsuka, H. Shimojo, M. Matsunaga et al., "Gene expression profiling of neural stem cells and identification of regulators of neural differentiation during cortical development," Stem Cells, vol. 29, no. 11, pp. 1817-1828, 2011.

[6] C. Qu, W. Li, Q. Shao et al., "c-Jun N-terminal kinase 1 (JNK1) is required for coordination of netrin signaling in axon guidance," Journal of Biological Chemistry, vol. 288, pp. 1883-1895, 2013.

[7] D. F. Sobieszczuk, A. Poliakov, Q. Xu, and D. G. Wilkinson, "A feedback loop mediated by degradation of an inhibitor is required to initiate neuronal differentiation," Genes and Development, vol. 24, no. 2, pp. 206-218, 2010.

[8] E. Utreras, E. M. Jiménez-Mateos, E. Contreras-Vallejos et al., "Microtubule-associated protein $1 \mathrm{~B}$ interaction with tubulin tyrosine ligase contributes to the control of microtubule tyrosination," Developmental Neuroscience, vol. 30, no. 1-3, pp. 200210, 2007.

[9] M. Geva, Y. Cabilly, Y. Assaf et al., "A mouse model for eukaryotic translation initiation factor 2B-leucodystrophy reveals abnormal development of brain white matter," Brain, vol. 133, no. 8, pp. 2448-2461, 2010.

[10] Z. Xiang, M. Valenza, L. Cui et al., "Peroxisome-proliferatoractivated receptor gamma coactivator $1 \alpha$ contributes to dysmyelination in experimental models of Huntington's disease," Journal of Neuroscience, vol. 31, no. 26, pp. 9544-9553, 2011.

[11] K.-H. Ling, C. A. Hewitt, T. Beissbarth et al., "Spatiotemporal regulation of multiple overlapping sense and novel natural antisense transcripts at the nrgn and camk $2 \mathrm{nl}$ gene loci during mouse cerebral corticogenesis," Cerebral Cortex, vol. 21, no. 3, pp. 683-697, 2011.

[12] D. J. P. Barker, "The origins of the developmental origins theory," Journal of Internal Medicine, vol. 261, no. 5, pp. 412-417, 2007.

[13] J. L. Tarry-Adkins, J.-H. Chen, R. H. Jones, N. H. Smith, and S. E. Ozanne, "Poor maternal nutrition leads to alterations in oxidative stress, antioxidant defense capacity, and markers of fibrosis in rat islets: potential underlying mechanisms for development of the diabetic phenotype in later life," FASEB Journal, vol. 24, no. 8, pp. 2762-2771, 2010.

[14] K. Boer, W. G. M. Spliet, P. C. van Rijen, F. E. Jansen, and E. Aronica, "Expression patterns of AMOG in developing human cortex and malformations of cortical development," Epilepsy Research, vol. 91, no. 1, pp. 84-93, 2010.

[15] Y. Fan, W. Zhu, M. Yang et al., "Del-1 gene transfer induces cerebral angiogenesis in mice," Brain Research, vol. 1219, pp. 1-7, 2008 .
[16] P. M. Wilson, R. H. Fryer, Y. Fang, and M. E. Hatten, "Astn2, a novel member of the astrotactin gene family, regulates the trafficking of ASTN1 during glial-guided neuronal migration," Journal of Neuroscience, vol. 30, no. 25, pp. 8529-8540, 2010.

[17] A. Dembinska-Kiéc, A. Polus, J. Grzybowska et al., "Nutritional factors and progenitor cell differentiation," Genes and Nutrition, vol. 2, no. 1, pp. 115-118, 2007.

[18] T. Ishiuchi, K. Misaki, S. Yonemura, M. Takeichi, and T. Tanoue, "Mammalian Fat and Dachsous cadherins regulate apical membrane organization in the embryonic cerebral cortex," Journal of Cell Biology, vol. 185, no. 6, pp. 959-967, 2009.

[19] H. Su, L. Wang, W. Huang et al., "Immediate expression of Cdh2 is essential for efficient neural differentiation of mouse induced pluripotent stem cells," Stem Cell Research, vol. 10, pp. 338-348, 2013.

[20] E. R. de Kloet, E. Vreugdenhil, M. S. Oitzl, and M. Joëls, "Brain corticosteroid receptor balance in health and disease," Endocrine Reviews, vol. 19, no. 3, pp. 269-301, 1998.

[21] A. P. Barnes, B. N. Lilley, Y. A. Pan et al., "LKB1 and SAD kinases define a pathway required for the polarization of cortical neurons," Cell, vol. 129, no. 3, pp. 549-563, 2007.

[22] M. F. Garces, E. Sanchez, B. J. Acosta et al., "Expression and regulation of chemerin during rat pregnancy," Placenta, vol. 33, no. 5, pp. 373-378, 2012.

[23] G. M. Yousef, T. Kishi, and E. P. Diamandis, "Role of kallikrein enzymes in the central nervous system," Clinica Chimica Acta, vol. 329, no. 1-2, pp. 1-8, 2003.

[24] T. L. Lewis Jr., T. Mao, and D. B. Arnold, "A role for Myosin VI in the localization of axonal proteins," PLoS Biology, vol. 9, no. 3, Article ID e1001021, 2011.

[25] S. Wirtz and M. Schuelke, "Region-specific expression of mitochondrial complex I genes during Murine Brain development," PLoS ONE, vol. 6, no. 4, Article ID e18897, 2011.

[26] V. Paakinaho, H. Makkonen, T. Jääskeläinen, and J. J. Palvimo, "Glucocorticoid receptor activates poised FKBP51 locus through long-distance interactions," Molecular Endocrinology, vol. 24, no. 3, pp. 511-525, 2010.

[27] L. Ni, C.-S. Yang, D. Gioeli, H. Frierson, D. O. Toft, and B. M. Paschal, "FKBP51 promotes assembly of the Hsp90 chaperone complex and regulates androgen receptor signaling in prostate cancer cells," Molecular and Cellular Biology, vol. 30, no. 5, pp. 1243-1253, 2010.

[28] Y. Huo, P. Rangarajan, E.-A. Ling, and S. T. Dheen, "Dexamethasone inhibits the Nox-dependent ROS production via suppression of MKP-1-dependent MAPK pathways in activated microglia," BMC Neuroscience, vol. 12, article 49, 2011.

[29] B. Budziszewska, M. Szymanska, M. Leskiewicz et al., "The decrease in JNK- and p38-MAP kinase activity is accompanied by the enhancement of PP2A phosphatase level in the brain of prenatally stressed rats," Journal of Physiology and Pharmacology, vol. 61, no. 2, pp. 207-215, 2010.

[30] H. Sakoda, Y. Gotoh, H. Katagiri et al., "Differing roles of Akt and serum- and glucocorticoid-regulated kinase in glucose metabolism, DNA synthesis, and oncogenic activity," Journal of Biological Chemistry, vol. 278, no. 28, pp. 25802-25807, 2003.

[31] W. Zhao, W. Qin, J. Pan, Y. Wu, W. A. Bauman, and C. Cardozo, "Dependence of dexamethasone-induced Akt/FOXO1 signaling, upregulation of MAFbx, and protein catabolism upon the glucocorticoid receptor," Biochemical and Biophysical Research Communications, vol. 378, no. 3, pp. 668-672, 2009. 
[32] M. Szymańska, A. Suska, B. Budziszewska et al., "Prenatal stress decreases glycogen synthase kinase-3 phosphorylation in the rat frontal cortex," Pharmacological Reports, vol. 61, no. 4, pp. 612620, 2009.

[33] A. Kapoor, S. Petropoulos, and S. G. Matthews, "Fetal programming of hypothalamic-pituitary-adrenal (HPA) axis function and behavior by synthetic glucocorticoids," Brain Research Reviews, vol. 57, no. 2, pp. 586-595, 2008.

[34] M. A. Cole, P. J. Kim, B. A. Kalman, and R. L. Spencer, "Dexamethasone suppression of corticosteroid secretion: evaluation of the site of action by receptor measures and functional studies," Psychoneuroendocrinology, vol. 25, no. 2, pp. 151-167, 2000.

[35] P. P. Le, J. R. Friedman, J. Schug et al., "Glucocorticoid receptordependent gene regulatory networks," PLoS Genetics, vol. 1, no. 2, Article ID 0010016, 2005. 


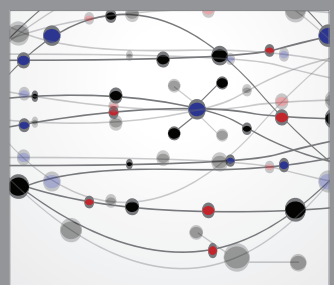

The Scientific World Journal
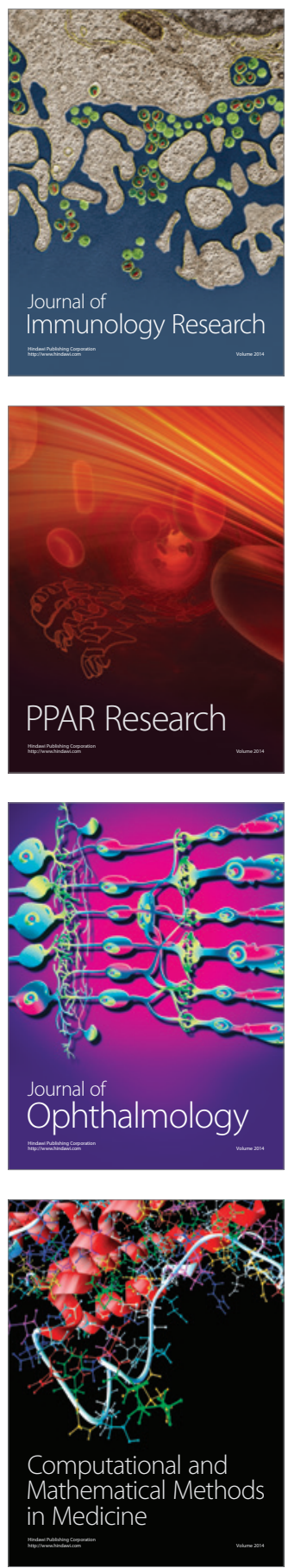

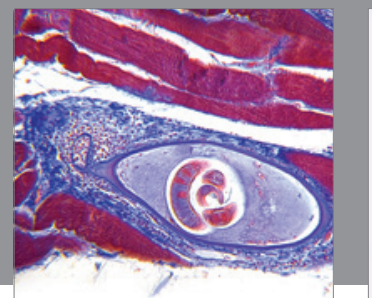

Gastroenterology

Research and Practice
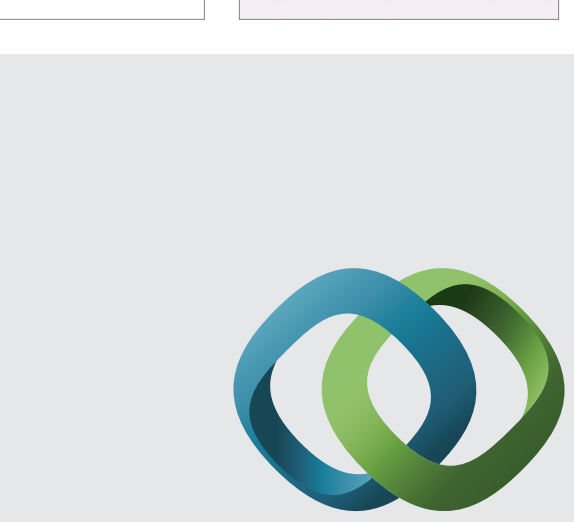

\section{Hindawi}

Submit your manuscripts at

http://www.hindawi.com
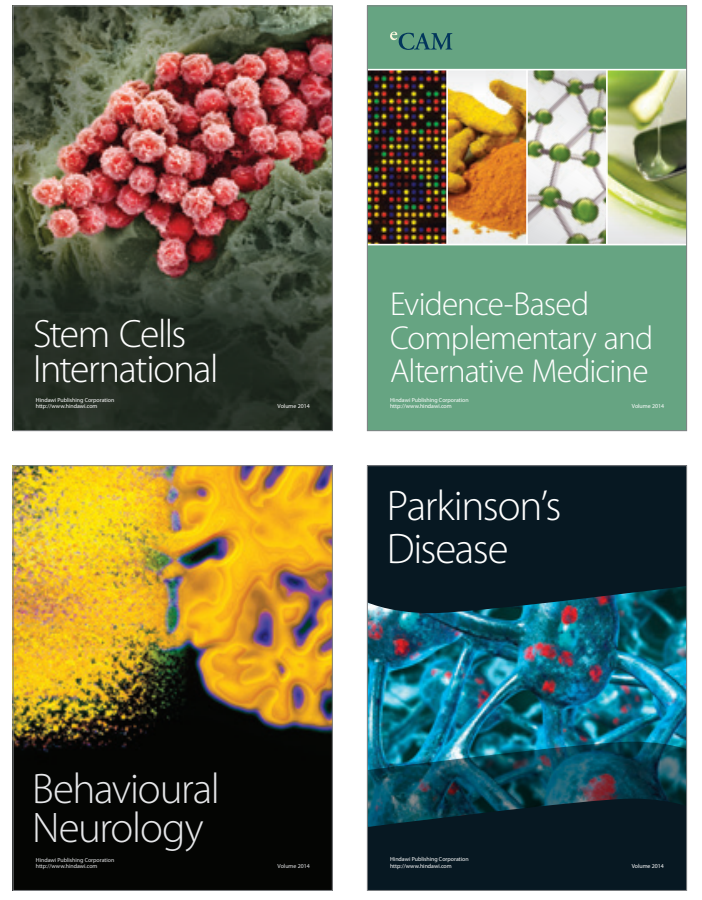
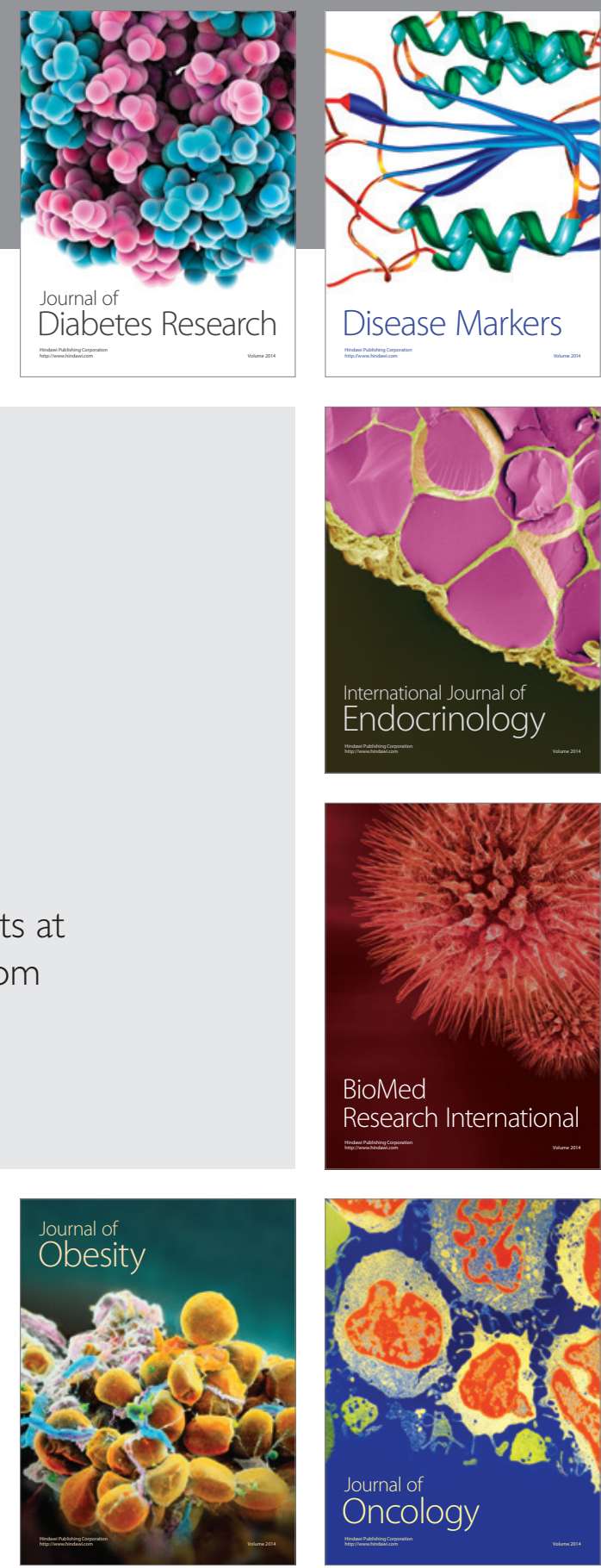

Disease Markers
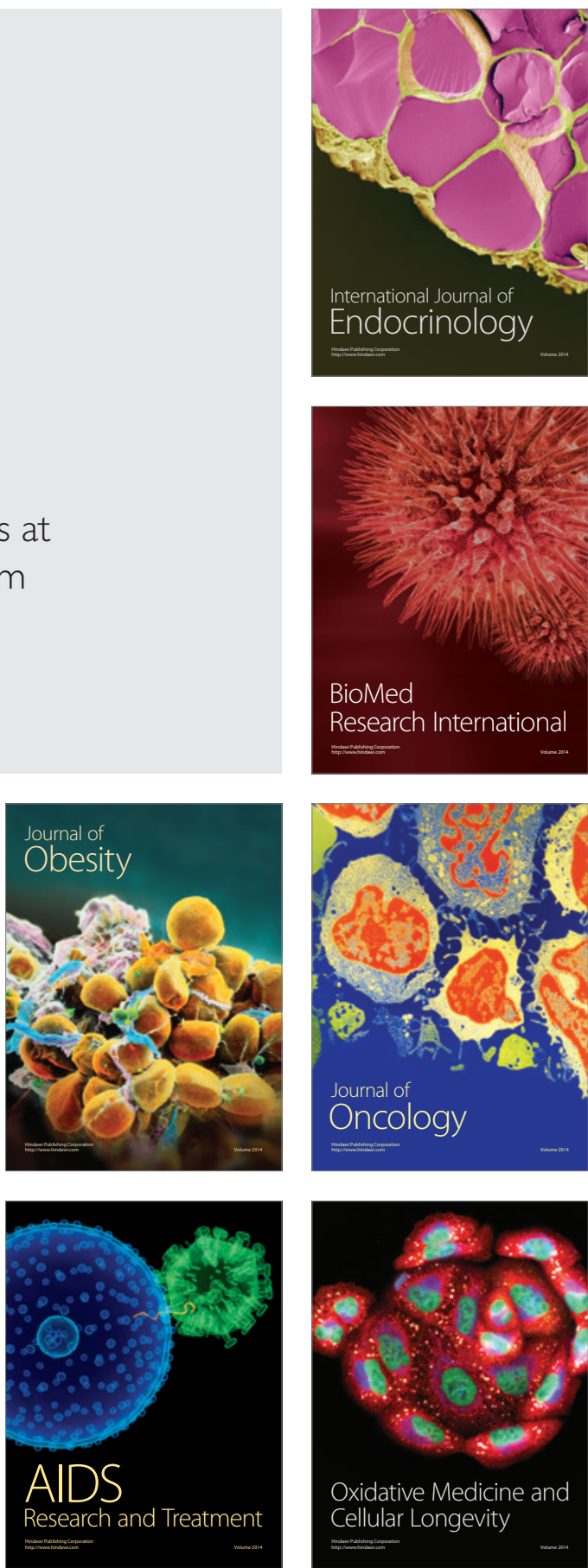